\title{
Quality of life of cervical cancer patients after completion of treatment - A study among Bangladeshi women
}

\author{
Hossain $\mathrm{N}^{1}$, Akter QM ${ }^{1}$, Banu $\mathrm{F}^{1}$, Mahmud $\mathrm{S}^{2}$ \\ ${ }^{1}$ Jr. Consultant Gynaeoncology, NICRH, Mohakhali, Dhaka, Bangladesh. ${ }^{2}$ Surgical specialist, BG \\ Hospital, Dhaka \\ Email: rumasharif_rafi@yahoo.com
}

\begin{abstract}
Cervical cancer is the main cause of malignancy-related death among women living in developing countries. The aim of this study is to evaluate the quality of life (QOL) among Bangladeshi cervical cancer survivors and its relationships with demographic and disease related factors

A cross-sectional study was carried out on one hundred nine consecutive cervical cancer survivors in National Institute of cancer Research and Hospital, Dhaka from September 2014 to february2015 using European organization for Research and treatment of cancer core Questionnaires (QOL-C30 and QOLCX24). Demographic condition like education level, occupation and disease related factors like stages, treatment modality and duration of follow-up time were taken as investigating factors against functional scales. Cronbach's alpha was calculated to asses' internal consistency among items.

Cervical cancer survivors stated a moderate QOL. Sub-domains of QOL score and global health status were significantly associated with physical function $(\mathrm{PF})$ scales $(\mathrm{p}=.000)$, fatigue $(\mathrm{p}=.045)$, nausea and vomiting $(\mathrm{p}=.000)$, Appetite loss $(\mathrm{p}=.001)$, constipation $(\mathrm{p}=.005)$, symptom experience $(\mathrm{p}=.005)$ and menopausal symptoms $(\mathrm{p}=.015)$. QOL mean score were negatively associated with emotional function(EF) scales, pain, fatigue, nausea, appetite loss and financial problems. Education level showed significant association with physical function $(\mathrm{PF})(\mathrm{p}=.001)$, emotional function $(\mathrm{EF})(\mathrm{p}=.027)$, Cognitive function $(\mathrm{CF})(\mathrm{p}=.000)$ and sexual function $(\mathrm{p}=.001)$. Duration (Follow-up) time was significance association with PF $(\mathrm{p}=.005), \mathrm{EF}(\mathrm{p}=.012)$, symptoms experience $(\mathrm{p}=.001)$. Although, the QOL in cervical cancer survivors was moderate, treatment of related symptoms and improvement of demographic condition can influence the QOL and survivors improve the care of cervical cancer. So, improve the QOL among cervical cancer survivors.
\end{abstract}

Key words: invasive cervical cancer, quality of life, Questionnaires, radical hysterectomy, radiotherapy

\section{Introduction}

About five lac women develop invasive carcinoma of the cervix per year around the world. Nearly $80 \%$ of the cases occur in developing countries. ${ }^{1}$ Cervical cancer was the second most common cancer in women in Bangladesh. With a prevalence of $21.1 \%$ among cancer in women. ${ }^{2}$ The effects of gynecological cancer on women health were multidimensional.
The age adjusted five-year relative survival rate for women who were treated for invasive carcinoma of the cervix is $71.2 \% .^{3}$ In Bangladesh, the clinical treatment for carcinoma cervix, especially radiotherapy, surgery, chemotherapy, or any combination of these, has sharply decreased the mortality of cervical cancer.

Disease and treatment of disease threatens not only life but also it perceived as a threat for reproductivity, sexuality and feminity. The 
chronic nature of the disease can affect the Quality of life (QOL) of these patients and their families.

In addition, psychological factor was usually involved in these patients include incorrect beliefs about the origin of cancer, changes in self-image, low self- esteem, marital tensions, fears and worries all of which can affect the patient QOL. ${ }^{4}$

QOL varies from culture-to-culture, nation-tonation. Demographic condition such as age, education level, occupation, marital status, social support affects the quality of life. 4-5 Clinical stages of disease, treatment modality, co morbidity such as HTN/CVD, depression, DM, hypothyroid, Asthma/COPD also affect QOL. ${ }^{5}$

Age, lower education level negatively affects the QOL but higher education level, employment status, marital status, social support affect positively on QOL. . $^{5-6}$

The patient with early cervical cancer shows better QOL than with advanced cervical cancer ${ }^{7}$. Treatment modality also affects the QOL, Women who receive combined treatment of cervical cancer by surgery and radiotherapy suffers from urinary incontinence which limit the patient activity, comfort and quality of life. ${ }^{8}$

Now a day, interest in investigation of the QOL in different diseases are increasing due to its potential value in identifying patient's problems and discovering the challenges and planning for the health system. ${ }^{9}$

Due to long term survival of cervical cancer patient's as a result of screening methods and its early treatment, study in the field of QOL and its related factors are important to improve the QOL among cervical cancer survivor. This was the first study in Bangladesh to evaluate the QOL and its associated factor among cervical cancer survivors.

\section{Materials and Methods}

This is a cross sectional study. Study population was patient histologically diagnosed as a primary carcinoma cervix who attends Gynecology OPD during follow up after completion of the treatment. (After 03 month of therapy). Sampling was purposive sampling and sample size was 109 cases. Inclusion criteria were histologically diagnosed as a primary cervical carcinoma, no other diagnosed malignancy, and treatment course completed > 3 months. Exclusion criteria were residual growth of disease and recurrence of disease. This study was conducted on gyneaoncology outdoor in National Institute of Cancer Research and Hospital, Dhaka, Bangladesh (NICRH). This was conducted from september2014 to February 2015. Formal permission was taken from place where the study carries out. The ethical committee and the institutional review board of the NICRH, Dhaka, Bangladesh was approved this study protocol.

First of all, the patient included in the study was informed about the purpose of the study and the verbal permission is taken.

A face-to-face interview method to administer the questionnaires by the researchers was used. Although EORTC QOL- C30 \& QOL- CX24 was a self-reporting questionnaires but in our situation it was not possible, so the investigators read the questionnaires items to the patient and recorded the answers. Disease related characteristics of the patient and demographic data was collected from pt and patient's file at the same sitting.

Instruments used for data collection:

EORTC (European organization for Research and Treatment of cancer) $Q O L-C 30$ : EORTC QOL C30(version 3) was a self-reporting cancer specific measure of QOL. It comprises a global health status/QOL scale and five multi item functions scale: physical function (PF), cognitive role functioning $(\mathrm{CF})$, emotional functioning $(\mathrm{EF})$ and social functionally (SF). Also six single items measure symptoms (dyspnea, insomnia, appetite loss, constipation, diarrhea and financial difficulties) and three multi item symptom scales assess fatigue, pain and nausea/ vomiting. Total 30 items, among them 28 were scored on fourpoint Liker scales and the remaining two items for the global health status/ QOL scales were scored on seven point scales. All scales were linearly transformed to a score from 0 to 100. A high score for a functional scale represents a high/ healthy level of functioning. A high score for global health status/ QOL, represent a high QOL, a high score for a symptom scale/ item represents a high level of symptoms/ problems. ${ }^{10}$

The questionnaires were also validated on different study. ${ }^{11}$ The Bangle version questionnaires was supplied by EORTC authority was used after getting their registration and approval. 
Cervical cancer Module QLO CX 24: The EORTC QLQ cervical cancer specific module (EORTC QLQ CX 24) was used which include all cervical cancer and its treatment related problems. It is composed of 24 questions assessing functional scales (body image, sexual activity, sexual enjoyment, sexual/vaginal functioning). And symptom scales related to treatment: symptoms experience lymph edema, peripheral neuropathy, menopausal symptoms and sexual worry. Sexual activity and sexual enjoyment, a higher score indicates better functioning.

Statistical method/data analysis: Patients included in this study were surveyed for the assessment of the quality of life with the questionnaires EORCT QOL-C30 and QOLCX24. Both questionnaires were grouped into global health, functional scales and symptoms scales. All scales ranges from 0 to 100 .

At first estimation of the average of all item was done which contribute to the scale; that was the raw score. Then a linear transformation was used to standardize the raw score. The raw score was converted into scales according to the EORCT scoring manual. Interpretations of scores were done by using Cohen's effect size (ES) which relates the observed change to the baseline standard deviation. Demographic and clinical data were calculated using descriptive statistics. Results of QOL information were expressed as mean, SD and correlation coefficient analysis. Nonparametric test and Chi-square test were used too determinant the association among categorical variables. $T$ test was used to determine the difference between any two variables or factors. A $\mathrm{p}$ value $<0.05$ was taken as statistically significant.

\section{Result}

One hundred and nine women with invasive cervical cancer who met the inclusion criteria were included in the study. In this study table I shows demographic and clinical data. The average mean age was $46 \pm 8$ with a range of $27-70$ years.

In terms of educational background, $42 \%$ was illiterate (no reading and writing) and 58\% literate (include primary, secondary, SSC and above). All women were housewife, none employed. Regarding marital status, $77 \%$ were married and $32 \%$ were widow. $56 \%$ have co morbidities and
53 have no morbidities. Co-Morbidities include DM, HTN/CVD, Asthma, COPD, and others.

Table I: Demographic and clinical data (n-109)

\begin{tabular}{|c|c|c|}
\hline variables & Description & \\
\hline Age & $\begin{array}{l}\text { Mean } \pm \text { SD } \\
\text { Range(min-max) }\end{array}$ & Freq. (\%) \\
\hline Education & $\begin{array}{l}\text { - Illiterate } \\
\text { - Primary(5class) } \\
\text { - Secondary(8class) } \\
\text { - SSC } \\
\text { - HSC and above }\end{array}$ & $\begin{array}{c}42(38.5) \\
33(30.3) \\
26(23.9) \\
17(6.4) \\
1(.9)\end{array}$ \\
\hline Occupation & $\begin{array}{l}\text { - Employment/worker } \\
\text { - House wife } \\
\text { - Married }\end{array}$ & $\begin{array}{c}0 \\
109(100) \\
77(70.6)\end{array}$ \\
\hline $\begin{array}{l}\text { Marital } \\
\text { status }\end{array}$ & $\begin{array}{l}\text { - Unmarried } \\
\text { - Divorced } \\
\text { - widow }\end{array}$ & $\begin{array}{c}0 \\
0 \\
32(29.4)\end{array}$ \\
\hline $\begin{array}{l}\text { Co } \\
\text { morbidities }\end{array}$ & $\begin{array}{l}\text { - No morbidities } \\
\text { - Morbidities }\end{array}$ & $\begin{array}{l}53(48.6) \\
56(51.4)\end{array}$ \\
\hline $\begin{array}{l}\text { Stages of } \\
\text { cervical } \\
\text { cancer }\end{array}$ & $\begin{array}{l}\text { - Stage1 } \\
\text { - Stage } 2 \\
\text { - Stage3 } \\
\text { - Stage4 }\end{array}$ & $\begin{array}{c}27(24.0) \\
69(63.3) \\
13(11.9) \\
0\end{array}$ \\
\hline $\begin{array}{l}\text { Treatment } \\
\text { modality }\end{array}$ & $\begin{array}{l}\text { - Radiotherapy } \\
\text { - Surgery } \\
\text { +Radiotherapy } \\
\text { - Radiotherapy } \\
\text { +Chemotherapy }\end{array}$ & $\begin{array}{l}48(44.0) \\
39(35.8)\end{array}$ \\
\hline $\begin{array}{l}\text { Follow up } \\
\text { time }\end{array}$ & $\begin{array}{l}\text { - } 3-12 \text { months } \\
\text { - } 1-2 \text { years } \\
\text { - > 2years }\end{array}$ & $\begin{array}{l}42(38.6) \\
26(23.9) \\
41(37.6)\end{array}$ \\
\hline
\end{tabular}

Stages of cervical cancer among Stage I- 24\%, Stage II-63\% and Stage III-11\%. Treatment modalities were Radiotherapy in- $20 \%$ cases, Surgery+ Radiotherapy in-44\%cases, and Radiotherapy+ chemotherapy in-35\% cases. Fellow-up (time since completion of treatment) duration were patients 3-12 months in 38\%, patients 1-2 years in $26 \%$ and patients $>2$ years in $41 \%$. EORCT- C30 and QOL-CX24 scores and association between global health statue and subdomains of the questionnaires shows in table I.

Global health status score was (mean \pm SD) $45 \pm 16$, range (0-83) which was poor. In symptoms higher score were in fatigue, pain, insomnia, appetite loss and financial problems. In QOLC30, sub-domains of QOL score were significantly associated with physical functioning 
(PF) in functional scales $(\mathrm{p}=.000)$ and presence of fatigue ( $p=0.045)$, Nausea and vomiting $(p=0.00)$, Appetite loss $(\mathrm{p}=0.002)$ and constipation $(p=0.015)$. Negative correlation coefficients mean negative effect on emotional functional scales, fatigue, pain, nausea and vomiting appetite loss, constipation and financial difficulties.

Table II: Correlation between Sub-Domains of the Questionnaires and Global Quality of life score.

\begin{tabular}{|c|c|c|c|c|}
\hline Sub-Domains & Mean \pm SD & Range & $\mathrm{p}$ & $\mathrm{R} * *$ \\
\hline \multicolumn{5}{|l|}{ EORTC QLQ-C30 } \\
\hline \multicolumn{5}{|l|}{ Functional Scales: } \\
\hline Physical functioning & $74 \pm 18$ & $26-100$ & $.000^{*}$ & .331 \\
\hline Role functioning & $65 \pm 21$ & $0-100$ & .425 & .078 \\
\hline Emotional functioning & $23 \pm 25$ & $0-100$ & .365 & -.088 \\
\hline Cognitive functioning & $63 \pm 25$ & $0-100$ & .383 & .085 \\
\hline Social functioning & $66 \pm 25$ & $0-100$ & .108 & .156 \\
\hline \multicolumn{5}{|l|}{ Symptom Scales: } \\
\hline Fatigue & $56 \pm 23$ & $0-100$ & .045 & -.194 \\
\hline Pain & $47 \pm 28$ & $0-100$ & .352 & -.092 \\
\hline Nausea and vomiting & $17 \pm 22$ & $0-100$ & $.000^{*}$ & -.418 \\
\hline \multicolumn{5}{|l|}{ Single items: } \\
\hline Dyspnoea & $15 \pm 27$ & $0-100$ & .687 & .039 \\
\hline Insomnia & $58 \pm 40$ & $0-100$ & .777 & .028 \\
\hline Appetite loss & $45 \pm 32$ & $0-100$ & $.002 *$ & -.232 \\
\hline Constipation & $33 \pm 34$ & $0-100$ & $.015^{*}$ & -.232 \\
\hline Diarrhea & $10 \pm 22$ & $0-100$ & .890 & .013 \\
\hline Financial problems & $63 \pm 30$ & $0-100$ & .804 & -.024 \\
\hline \multicolumn{5}{|l|}{ EORTC QLO-CX24 } \\
\hline \multicolumn{5}{|l|}{ Functional scale: } \\
\hline Body image(CXBI) & $97 \pm 17$ & $0-77$ & .162 & -.135 \\
\hline $\begin{array}{l}\text { Sexual } \\
\text { activity }(\mathrm{CXSXA})(\mathrm{n}-35)\end{array}$ & $42 \pm 29$ & $0-100$ & .442 & -.075 \\
\hline $\begin{array}{l}\text { Sexual } \\
\text { enjoyment(CXSXE) }\end{array}$ & $26 \pm 30$ & $0-100$ & .182 & -.198 \\
\hline Sexual & $35 \pm 23$ & $0-100$ & .954 & -.006 \\
\hline Functioning(CXSV) & & & & \\
\hline Symptom scales: & & & & \\
\hline $\begin{array}{l}\text { Symptom } \\
\text { experience(CXSE) }\end{array}$ & $37 \pm 17$ & $6-84$ & $.005^{*}$ & -.271 \\
\hline Lymhoedema(CXLY) & $15 \pm 29$ & $0-99$ & .509 & .064 \\
\hline $\begin{array}{l}\text { Peripheral } \\
\text { neuropathy(CXPN) }\end{array}$ & $51 \pm 31$ & $0-100$ & .233 & -.116 \\
\hline $\begin{array}{l}\text { Menopausal } \\
\text { symptoms(CXMS) }\end{array}$ & $66 \pm 37$ & $0-100$ & $.013^{*}$ & .237 \\
\hline Sexual worry(CXSW) & $51 \pm 45$ & $0-100$ & .873 & .016 \\
\hline
\end{tabular}

In QOL-CX24, QOL score were significantly associated with symptom experiences $(\mathrm{p}=0.005)$ and menopausal symptoms $(\mathrm{p}=0.013)$. It showed negative impact on body image, sexual functioning, symptom experiences and peripheral neuropathy.

Association between independent variables age, education, marital status, co morbidities, stages of disease, treatment modality, fellow-up time and dependent variables at QOL functional scales shows in table III.

Age <40years showed higher mean score of physical function $(\mathrm{PF})$, emotional function $(\mathrm{EF})$, cognitive function (CF) than age >40years but no statistically significance among them.

Table III: Association among oncological variable and QOL functional scales (QOL-C30).

\begin{tabular}{|c|c|c|c|c|c|c|c|c|}
\hline \multirow{4}{*}{$\begin{array}{l}\begin{array}{c}\text { Oncological } \\
\text { factor }\end{array} \\
\text { Age }\end{array}$} & \multirow{4}{*}{$\begin{array}{l}\text { Description } \\
\text { >=40years } \\
<40 \text { years }\end{array}$} & \multirow[t]{2}{*}{$\mathrm{n}$} & \multicolumn{2}{|c|}{$\begin{array}{l}\text { Physical } \\
\text { function } \\
\text { scales }\end{array}$} & \multicolumn{2}{|c|}{$\begin{array}{l}\text { Emotional } \\
\text { function } \\
\text { scales }\end{array}$} & \multicolumn{2}{|c|}{$\begin{array}{l}\text { cognitive } \\
\text { function } \\
\text { scales }\end{array}$} \\
\hline & & & Mean & $\mathrm{p}$ & Mean & $\mathrm{p}$ & Mean & $\mathrm{p}$ \\
\hline & & & 62.50 & & 53.09 & & 59.64 & \\
\hline & & & 52.15 & .13 & 55.02 & .77 & 52.61 & .30 \\
\hline \multirow{5}{*}{ Education } & & & Mean & $\mathrm{p}$ & Mean & $\mathrm{p}$ & Mean & $\mathrm{p}$ \\
\hline & Illiterate & & 52.99 & & 59.25 & & 43.87 & \\
\hline & Primary & & 54.98 & & 46.83 & & 64.42 & \\
\hline & Secondary & & 44.69 & .00 & 47.72 & $.03 *$ & 47.32 & .00 \\
\hline & $\begin{array}{l}\text { SSC and } \\
\text { above }\end{array}$ & & 97.72 & & 78.72 & & 89.50 & \\
\hline \multirow{3}{*}{$\begin{array}{l}\text { co } \\
\text { morbidities }\end{array}$} & \multirow{4}{*}{$\begin{array}{l}\text { No } \\
\text { morbidities } \\
\text { morbidities }\end{array}$} & & Mean & $\mathrm{p}$ & Mean & $\mathrm{p}$ & Mean & $\mathrm{p}$ \\
\hline & & 53 & 59.57 & .14 & 52.38 & .48 & 56.98 & .42 \\
\hline & & 56 & 50.68 & & 56.47 & & 52.20 & \\
\hline \multirow{4}{*}{$\begin{array}{l}\text { Tumor } \\
\text { stage }\end{array}$} & & & Mean & $\mathrm{p}$ & Mean & $\mathrm{p}$ & Mean & $\mathrm{p}$ \\
\hline & Stage1 & 27 & 59.17 & & 46.20 & & 47.98 & \\
\hline & Stage2 & 69 & 57.14 & .05 & 56.64 & .23 & 51.93 & .30 \\
\hline & Stage3 & 13 & 34.96 & & 60.83 & & 49.46 & \\
\hline \multirow{4}{*}{$\begin{array}{l}\text { Treatment } \\
\text { modality }\end{array}$} & & & Mean & $\mathrm{p}$ & Mean & $\mathrm{p}$ & Mean & $\mathrm{p}$ \\
\hline & Radiotherapy & 22 & 52.43 & & 46.20 & & 47.98 & \\
\hline & $\begin{array}{l}\text { Surgery+ } \\
\text { Radiotherapy }\end{array}$ & 48 & 62.21 & .09 & 56.64 & .23 & 51.98 & .30 \\
\hline & $\begin{array}{l}\text { Radiotherapy+c } \\
\text { hemotherapy }\end{array}$ & 39 & 47.58 & & 60.83 & & 49.46 & \\
\hline \multirow{4}{*}{$\begin{array}{l}\text { Follow } \\
\text { time }\end{array}$} & & & Mean & $\mathrm{p}$ & Mean & $\mathrm{p}$ & Mean & $\mathrm{p}$ \\
\hline & 3-12months & 42 & 48.27 & & 41.27 & & 52.55 & \\
\hline & $1-2$ years & 26 & 41.56 & .01 & 52.60 & .01 & 55.08 & .840 \\
\hline & $>2$ years & 41 & 65.54 & & 64.29 & & 57.12 & \\
\hline
\end{tabular}

"Follow time (time since completion of treatment)

Co morbidities with disease had lower mean score of $\mathrm{PF}, \mathrm{EF}, \mathrm{CF}$ than no morbidities but findings were statistically nonsignificant. Education level showed significant association with $\mathrm{PF}(\mathrm{p}=0.001)$, $\mathrm{EF}(\mathrm{p}=0.027)$ and $\mathrm{CF}(\mathrm{p}=0.000)$.

Advance stages of cervix (stage3) showed lower mean score of PF and significant association $(\mathrm{p}=.047)$ with. Regarding follow-up duration, >2years follow-up time showed higher mean score of PF and EF than others. Follow-up time (>2years) showed significant association among $\mathrm{PF}(\mathrm{p}=.005)$ and $\mathrm{EF}(\mathrm{p}=, 012)$.

Any association between independent variables and QOL-CX24 scales shows in table IV, higher education level showed higher mean score of sexual functioning and lower score of symptom experience. So, higher education level showed Significance association with sexual functioning (CXSV) $(\mathrm{p}=.033)$ and Symptoms experiences $(\mathrm{p}=.001)$. No significance between age, co morbidities, stages, treatment modality and follow- up time with sub-domains of QOL-CX24 
Table IV: Association among Oncological factor and QOL CX24 scales

\begin{tabular}{|c|c|c|c|c|c|c|c|}
\hline \multirow{4}{*}{$\begin{array}{l}\text { Oncologic } \\
\text { al factor }\end{array}$} & \multirow{5}{*}{$\begin{array}{l}\text { Description } \\
\\
<=40 \text { years } \\
>40 \text { years }\end{array}$} & \multicolumn{2}{|c|}{$\begin{array}{c}\text { Sexual } \\
\text { functioning } \\
(\mathrm{CXSV})\end{array}$} & \multicolumn{2}{|c|}{$\begin{array}{l}\text { Symptom } \\
\text { experience } \\
\text { (CXSV) }\end{array}$} & \multicolumn{2}{|c|}{$\begin{array}{c}\text { Menopausal } \\
\text { Symptom } \\
\text { (CXMS) }\end{array}$} \\
\hline & & Mean & $\mathrm{p}$ & Mean & $\mathrm{p}$ & Mean & $\mathrm{p}$ \\
\hline & & 55.88 & & 46.72 & & 58.31 & 415 \\
\hline & & 53.99 & .18 & 57.35 & .12 & 53.10 & .415 \\
\hline \multirow{6}{*}{ Education } & & Mean & $\mathrm{p}$ & Mean & $\mathrm{p}$ & Mean & $\mathrm{p}$ \\
\hline & \multirow{5}{*}{$\begin{array}{l}\text { Illiterate } \\
\text { Primary } \\
\text { Secondary } \\
\text { SSC and } \\
\text { above }\end{array}$} & 55.27 & & 53.14 & & 52.17 & \\
\hline & & 50.89 & & 60.11 & & 48.92 & \\
\hline & & 47.28 & $.03 *$ & 60.10 & $.00^{*}$ & 63.06 & .305 \\
\hline & & 85.00 & & 8.57 & & 56.57 & \\
\hline & & Mean & $\mathrm{p}$ & Mean & $\mathrm{p}$ & Mean & $\mathrm{p}$ \\
\hline \multirow[t]{2}{*}{$\begin{array}{l}\text { Co } \\
\text { morbidities }\end{array}$} & No morbidities & 54.33 & \multirow{2}{*}{.96} & 50.08 & \multirow[t]{2}{*}{.16} & 56.98 & \multirow[b]{2}{*}{.399} \\
\hline & morbidities & 54.66 & & 58.61 & & 52.20 & \\
\hline \multirow{4}{*}{$\begin{array}{l}\text { Stages of } \\
\text { disease }\end{array}$} & & Mean & $\mathrm{p}$ & Mean & $\mathrm{p}$ & Mean & $\mathrm{p}$ \\
\hline & Stage1 & 46.17 & \multirow{3}{*}{.17} & 53.89 & & 60.02 & \multirow{3}{*}{.494} \\
\hline & Stage2 & 55.92 & & 52.45 & .30 & 52.14 & \\
\hline & Stage3 & 65.08 & & 67.67 & & 55.62 & \\
\hline \multirow{4}{*}{$\begin{array}{l}\text { Treatment } \\
\text { modality }\end{array}$} & & Mean & $\mathrm{p}$ & Mean & $\mathrm{p}$ & Mean & $\mathrm{p}$ \\
\hline & Radiotherapy & 61.75 & \multirow{3}{*}{.09} & 51.23 & \multirow{3}{*}{.09} & 53.09 & \multirow{3}{*}{677} \\
\hline & $\begin{array}{l}\text { Surgery+ } \\
\text { Radiotherapy }\end{array}$ & 58.29 & & 48.74 & & 52.41 & \\
\hline & $\begin{array}{l}\text { Radiotherapy+ } \\
\text { chemotherapy }\end{array}$ & 45.85 & & 63.28 & & 57.81 & \\
\hline \multirow{4}{*}{$\begin{array}{l}\text { Follow up } \\
\text { time } \\
\text { (time since } \\
\text { completion } \\
\text { of } \\
\text { treatment }\end{array}$} & & Mean & $\mathrm{p}$ & Mean & $\mathrm{p}$ & Mean & $\mathrm{p}$ \\
\hline & 3-12 month & 42.95 & .06 & 61.24 & .09 & 51.25 & \multirow{3}{*}{.625} \\
\hline & 1-2years & 53.95 & & 61.84 & & 59.69 & \\
\hline & $>2$ years & 62.34 & & 48.07 & & 55.78 & \\
\hline
\end{tabular}

\section{Discussion}

Traditionally, oncologists have focused their efforts on maximizing the overall survival of their patients. Although many oncologists acknowledge that QOL after cancer therapy is an important aspect of patient's care. Today, QOL surveys are an important issue in health care, especially in oncological research. Cancer affects different aspect of QOL and now a day, it is a major problem all over the world. The time of diagnosis \& the initial stages of treatment are the most difficult time for women both physically and emotionally.

This study examined the QOL among cervical cancer women in Bangladeshi population especially in the under privileged sector in the society in a public hospital.

The mean age was $46.43 \pm 8$, range (27-70). Most of the women were premenopausal. Global health status /scales were $45 \pm 16$ which consider poor.

When the sub-dimension of the quality of life scales were evaluated, the physical function score (PF), Role function(RF), Cognitive function(CF) score and social function (SF) score were good but negative impact seen on emotional function score which was poor. So, this study showed moderate score of the total QOL score. In Reis $\mathrm{N}$ study ${ }^{12}$, had moderate score of the total quality of life score which was similar to this finding. In Pinars $\mathrm{G}$ study ${ }^{13}$ by using EORCT QOL-C30 with patient diagnosed with gynecology cancer, quality of life was determined to be low. In symptom scales-fatigue, pain, nausea and vomiting, appetite loss, constipation negatively affected the physical wellbeing. This similar finding was found Deshields TL study ${ }^{14}$ were the patients physical wellbeing was found to be low $\&$ patients reported that fatigue, insomnia, pain were the common complaints. In current study, the most frequent symptoms were fatigue, pain, insomnia, appetite loss and financial problems. In NazikE study ${ }^{15}$ patients with gynecological cancer most frequently reported symptoms fatigue, loss of wellbeing, pain, nausea and appetite. Akin and durma study ${ }^{16}$ patient with cancer most frequently reported experiencing were tiredness, loss of wellbeing, anxiety, appetite changes, pain and nausea. Both study finding similar to current study. In this study, EF score was found to be low and negatively impact on QOL. Similar finding found to the Reis $\mathrm{N}^{12}$ study of psychological wellbeing was affected area. In a study ${ }^{17}$ mean score on the emotional wellbeing subscale was slightly lower than normative data women in the general population. One Brazilian study ${ }^{18}$ found that after 2 years of treatment QOL and mental health of cervical cancer survivors were similar to those without malignancy. This was different in current study, probably due to mean time of follow-up. A European study ${ }^{4}$ showed no significant correlation between QOL and emotional function which was not similar to this finding.

QOL-CX24 questionnaire in this study showed negative impact on Body image. Only 35 respondents have sexual activity. Among them showed negative impact on sexual activity, sexual enjoyment and sexual functioning. Similar finding that problem with sexual activity and other symptoms were observed among patient who underwent radiotherapy found in Korfage IJ study. ${ }^{19}$ In current study, women reported more sexual worry. Negative impact on sexuality across all cervical patients was found in several studies. ${ }^{20-24}$ In this study most of the patients were premenopausal, so negative effects have been observed in sexual/vaginal functioning for this group of patient. Similar finding found that 
negative impact on the vaginal functioning for younger patients in a European study. ${ }^{5}$

In this study, a negative association was observed between QOL score and menopausal symptoms. Similar finding found in one study, the presence of menopausal symptoms had a negative impact on QOL. ${ }^{4,25}$

Active treatment in associated with a negative effect on most QOL domains compared to being in follow-up. All domains except lymph edema and peripheral neuropathy improved during follow-up. Lymphoedema is a risk after treatment of cervical cancer ${ }^{26-27}$ but seldom assed and reported. In this study, peripheral neuropathy score was negatively associated with QOL score. Cognitive function and peripheral neuropathy worsened with time, probably as a late side-effect of therapy especially chemotherapy. ${ }^{5}$ There is a lack of data in the literature on late toxicity after treatment and this need to be studied further.

In this study many demographic and clinical data compare to functional scales of QOL-C30 and QOL-CX24, as age was categorized as $=<40$ years and $>40$ years. Although PF score, EF score, CF score were higher in $=<40$ years than $>40$ years but not statistically significant. Similar result showed in one European study. ${ }^{5}$ Chi-square test shows strong association between level of education and function score of PF, EF, and CF. Co- morbidities also consider which affect the overall QOL. Women have no morbidities showed high mean score of PF, EF, CF scales than women have co-morbidities but there were no statistically significant association. In this study, advance stage of disease showed poor mean score of PF which was statistically significant. Regarding the disease stages and QOL one study ${ }^{28}$ reported that QOL in survivors of advanced stages of cervical cancer had not reach the QOL of healthy women by 18 months after diagnosis which was similar to this finding. In this study treatment modality of disease did not affect the functional scales of QOL. Similar result show one study ${ }^{3}$ after two years of complete treatment, QOL and $\mathrm{MH}$ were similar and were not affected by modality of treatment. But in contrast, Bradley ${ }^{29}$ concluded that QOL was not related to disease characteristics include treatment modality and stage of disease. One study ${ }^{30}$ show significant difference between QOL according to disease stage. In contrast, after correcting for age and stage, to be treated with surgery plus other therapy were associated with more impairment of QOL. ${ }^{5}$ In this study, time of follow-up was important, patients who completed treatment and disease free $>2$ years, mean $\mathrm{PF}$ score, FE score, CF score were higher than $<2$ years' time. In this study PF score and FE score were statistically significance with duration of follow-up. One Brazilian study ${ }^{3}$ after at least two years, QOL and $\mathrm{MH}$ of women treated for invasive cervical cancer were similar to those of women without malignancy and were not affected by the modalities of treatment.

In this study sexual functioning (CXSV) score was high in higher education level than lower education level and symptoms experience score was lower among higher education level than lower education level, but no statistically significant

This study had some limitation. This study was a cross sectional study. But a longitudinal study could be expected to demonstrate the related variables during the course of time. We did not include social support, spiritual factor and family income; all of them affect QOL. In future, required further research.

Conclusion: In conclusion, variation among the tools for assessing QOL in women with cervical cancer survivors was too broad. In this study, the QOL in cervical cancer survivors was moderate. It is suggested that the scales with lower scores, particularly in emotional function scales should be the subjects of more precise attention and effective intervention in order to provide a better QOL during and after treatment. Although QOL in cervical cancer survivors was moderate, treatment of related symptoms can influence the QOL and improve the care of cervical cancer survivors.

\section{References}

1. American cancer society. Cancer Facts and figures 2010. Atlanta, CA; American cancer society ,2010. Last accessed january 6,2011.

2. Cancer Registry Report (2008-2010), NICRH, Bangladesh.

3. National cancer Institute. Age-Adjested seer incidence and U.S death rates and 5-years relation survival rates. National cancer institute 2004. Accessed january18,2009.

4. Fernandes WC, Kimura M. Health related quality of life of women with cervical cancer. Rev lat Am Enfermagem 2010;18(3):360-70. 
5. Vesna Bjelic-radisic, Pernille T. Jensen, Karim Kuljanic Vlasic et al. Quality of life characteristics inpatients with cervical cancer. European journal of cancer (2012)48, 3009-3018. Available at www.sciencedirect.com

6. Evsen Nazik ${ }^{1}$, Hakan Nazik ${ }^{2}$, Funda Ozdemir ${ }^{3}$ et al. Social support and Quality of life in Turkish patient with Gyneacologic cancer. APJCD vol $15,2014(3081)$

7. Yao $\mathrm{Xie}^{1}$, Fang-Hui Zhoa ${ }^{2}$ Si-Han $\mathrm{Lu}^{3}$ et al. Assessment of Quality of life for the patients with cervical cancer at different clinical stages. Chinese Journal of cancer 2013; vol32 issue5.

8. Dzenita Ljuca ${ }^{1}$, Goran Marosevic ${ }^{2}$ et al. Quality of life in patients with cervical cancer FIGO11b stage after concomitant chemoradiotherapy. Radical oncol2009;43(4):293-298.

9. Shahnaz Torkzahranis ${ }^{1}$, Leila Rastegari ${ }^{2}$, Alireza Akbarzadeh-Baghi-an ${ }^{3}$ et al. Quality of life and its related factors among Iranian cervical cancer survivors. Iranian Red crescent Medical Journal $2013 ; 15(4)$

10. Aaronson $\mathrm{NK}^{1}$, Ahmedzai $\mathrm{S}^{2}$, BergmanB $^{3}$ el at. The European organization for Research and Treatment of cancer QOL-C30: A quality of life instrument for use in international clinical trials in oncology. $\mathrm{J}$ Natl Cancer 1993;85;365-76.

11. Elfried R. ${ }^{1}$, Karin Kuljanic ${ }^{2}$, Ann-Charlotte ${ }^{3}$ et al. The European organization of Research and Treatment of cancer (EORTC) Quality-of-life Questionnaire cervical cancer module. (EORTC QOL-CX24). The EORTC cervical cancer module,cancer oct 15,2006/vol107/num8(1812-1823).

12. www.interscience.wiley.com

13. Reis $\mathrm{N}^{1}$, Beji $\mathrm{NK}^{2}$, Coskun $\mathrm{A}^{3}$ et al. Quality of life and sexual functions in gynecological cancer patients: result from qualitative and quantitative data. Eur Joncol nurs 2010;14(137-46).

14. Pinar $\mathrm{G}^{1}$, Okden $\mathrm{s}^{2}$, Buyukgonencl ${ }^{3}$, el at. The relationship between support and level of anxiety, depression and Quality of life of Turkish women with gynecologic cancer. Cancer Nurs .2012;35 (229-35).

15. Deshields TL ${ }^{1}$, Potter $\mathrm{P}^{2}$, Olsens ${ }^{3}$, el at. Documenting the symptoms experience of cancer patients. J support oncol.2011;9(216-23).

16. Nazik E $E^{1}$, Arslans ${ }^{2}, \mathrm{Nazikh}^{3}$ et al. Anxiety and symptoms assessing in Turkish Gynecological cancer patients receiving chemotherapy. Asians Pac J cancer Pre.2012;13(3129-33)

17. Akin $S^{1}$, Durna $Z^{2}$ et al. A comparative descriptive study examining the perception of cancer patients, family care givers and nurses on patient symptoms severity in Turkey. EurJ.oncol. Nurs.2013:17(30-7)

18. Gil $\mathrm{Km}^{1}$, Gibbons $\mathrm{HE}^{2}$, Jenison $\mathrm{EL}^{3}$ et al. Baseline characteristics influencing Quality of life in women undergoing gynecologic oncology surgery. Health Qual life outcome.2007;17(1-7).

19. Park $\mathrm{SY}^{1}, \mathrm{Bae} \mathrm{DS}^{2}, \mathrm{Nam} \mathrm{JH}^{3}$, et al. Quality of life and sexual problems in disease-free survivors of cervical cancer compared with general population. Cancer.2007;110(2716-25)

20. Korfage $\mathrm{IJ}^{1}$, Essink-Bot $\mathrm{ML}^{2}$, Mols $\mathrm{F}^{3}$ et al. Health related quality of life in cervical cancer survivors:a population based survey. Int,.J.Radiat oncol Biol Phys 2009;73;5(1501-9).

21. Klee $\mathbf{M}^{1}$, Thranov $\mathrm{I}^{2}$, Machin $\mathrm{D}^{3}$, et al. Life after radiotherapy: A psychological and social effect experiences by women treated for advanced stages of cervical cancer. Gynecol oncol 2000; 76 ; (5-13).

22. Kullmer $\mathrm{U}^{1}$, stinger $\mathrm{K}^{2}$, Milch $\mathrm{W}^{3}$, et al. Self-concept, body image and use of unconventional therapies in patients with gynaecological malignancies in the state of complete remission and recurrence Eur J Obst Gyneal. Reprot Biol.1999;82(101-6).

23. Jensen $\mathrm{PT}^{1}$, Groenvold $\mathrm{M}^{2}$, Klee $\mathrm{Mc}^{3}$, et al. Longitudinal study of sexual function and vaginal changes after radiotherapy for cervical cancer. Int.J.Red oncol boil phys, 2003;569:937-49)

24. Bergmark $\mathrm{K}^{1}$, Avall-Lundq $\mathrm{E}^{2}$, Dickman $\mathrm{PW}^{3}$, el at. Patients-rating of distressful symptoms after treatment for early cervical cancer. Acta Obstet Gynecol Scand. 2002;81(443-50).

25. Shah $\mathrm{AA}^{1}$, Beinecke $\mathrm{RH}^{2}$, Global mental health needs services, barriers, and challenges. Int Ment Health; 2009:38;(1)14-29.

26. Rrayan $\mathrm{M}^{1}$, Stainton $\mathrm{MC}^{2}$, Slaytor $\mathrm{EK}^{3}$ et al Etiology and prevalence of lower limb lymphedema following treatment for gynaecological cancer. Aust N Z J obstet gynaecol 2003;43(184-51).

27. Werngren-Elgstrom $\mathrm{M}^{1}$, Lidman $\mathrm{D}^{2}$. Lymphedema of the lower Extremities after surgery and radiotherapy for cancer of the cervix. Second $J$ Plast. Reconstr,surg.hand.surg 1994:28(289-93)

28. Klee $\mathbf{M}^{1}$, Thranov ${ }^{2}$, Machin $\mathrm{D}^{3}$ et al. Life after radiotherapy: the psychological and social effects for advanced stages of cervical cancer. Gynaecol oncol:2001;76;(5-13)

29. Bradley $S^{1}$, Rose $S^{2}$, Lutgendrof $S^{3}$ et al. Quality of life and Mental health in cervical and endometrial cancer survivors. Gynecol oncol.2006;100(479-48).

30. Mika kobayash ${ }^{1}$, Tatsuya $\mathrm{O}^{2}$, Wataru $\mathrm{N}^{3}$ et al. Psychological distress and quality of life in cervical cancer survivors after radiotherapy. InterJof Gye.cancer 2009;19;(1264-68)

31. Michael $\mathrm{F}^{1}$, Charlottec ${ }^{2}$ et al. Quality of life and Sexual functions in cervical cancer survivors. $J$ of Clinical oncol.2005;23;30;(7428-36). 